\title{
Clinical Trial Management Communication and Tracking Document
}

National Cancer Institute

\section{Source}

National Cancer Institute. Clinical Trial Management Communication and Tracking

Document. NCI Thesaurus. Code C115656.

Records pertaining to the management and tracking of a clinical trial. 